\title{
BMJ Open Interprofessional education in the care of people diagnosed with dementia and their carers: a systematic review
}

\author{
Marcus Jackson, Ferruccio Pelone, Scott Reeves, Anne Marie Hassenkamp, \\ Claire Emery, Kumud Titmarsh, Nan Greenwood
}

To cite: Jackson M, Pelone F, Reeves S, et al. Interprofessional education in the care of people diagnosed with dementia and their carers: a systematic review. BMJ Open 2016;6:e010948. doi:10.1136/bmjopen-2015010948

- Prepublication history and additional material is available. To view please visit the journal (http://dx.doi.org/ 10.1136/bmjopen-2015010948).

Received 22 December 2015 Revised 16 June 2016 Accepted 26 July 2016

CrossMark

Faculty of Health, Social Care and Education, Kingston University and St George's, University of London, London, UK

Correspondence to Dr Nan Greenwood; nan.greenwood1@gmail.com

\section{ABSTRACT}

Objectives: This systematic review is linked to the multifaceted social, economic and personal challenges of dementia and the international recognition of the value of interprofessional education (IPE) and its influence on health and social care outcomes. This review therefore aimed to identify, describe and evaluate the impact of IPE interventions on health and social care practitioners (prequalification and postqualification) understanding of dementia, the quality of care for people with dementia and support for their carers.

Methods: Following PRISMA guidelines, 9 databases were searched (MEDLINE, EMBASE, The Cochrane Library, PsycINFO, CINAHL Plus, Applied Social Sciences Index and Abstracts, Healthcare Management Information Consortium, ERIC and British Education Index). Narrative analysis of the findings was undertaken.

Design: Systematic review.

Results: 6 studies meeting the inclusion criteria were identified. The majority of studies were conducted in North America. Participants in 4 studies were health and social care practitioners caring for people with dementia, whereas the remaining studies focused on training graduate or undergraduate students. Diverse IPE activities with varying content, delivery mode and duration were reported. Although some studies reported more positive attitudes to interprofessional working as a result of the interventions, none reported benefits to patients or carers. The quality of the included studies varied. Overall, the evidence for the reported outcomes was considered weak.

Conclusions: This review identified 6 studies describing IPE interventions intended to improve collaborative knowledge, skills, interprofessional practice and organisational awareness of dementia and dementia care. The small number of studies, their varied nature, scope and settings combined with poor quality of evidence limits our understanding of the effectiveness of IPE on the care and support of people with dementia and their carers. Further research is required to develop the evidence base and provide robust studies to inform IPE development.

Trial registration number: CRD42014015075.

\section{Strengths and limitations of this study}

- The methods were rigorous and based on the Preferred Reporting Items for Systematic review and Meta-analysis Protocols (PRISMA-P) 2015 statement and on prospective registered protocol that was followed thorough.

- Strengths of this review include its extensive and systematic search of various databases, its screening and data collection process conducted independently by two authors and the use of the GRADE approach to assess confidence in estimates of effect.

- The results of this systematic review are likely to be influenced by language, search and selection bias.

- We identified only six studies, and the overall quality of evidence for each investigated outcome was low to very low, hence we could not draw strong conclusions.

\section{INTRODUCTION}

Dementia is a syndrome with symptoms that include changes in memory capacity, personality and behaviour. ${ }^{1}$ These symptoms, to varying degrees, may result in a decline in autonomy and impact on an individual's agency for independent living. ${ }^{2}$ The current worldwide estimate of people affected by dementia is in excess of 35 million and rising, ${ }^{3}$ and dementia is now widely acknowledged as a significant public health issue. ${ }^{45}$

Although not exclusively, dementia is primarily age related with a standardised prevalence occurring at 60 years of age. ${ }^{6}$ This has great significance given that the world's population aged 60 and above will reach 1.25 billion by $2050 .^{7}$ While such age-related epidemiological projections are challenging, the economic and societal costs of dementia that are likely to increase year on year ${ }^{9}$ remain unquestionable.

Residential care is often necessary in latestage dementia when patients may suffer from continence problems, immobility when 
they are bedridden or behavioural problems. ${ }^{10}$ However, in most cases, the burden of caring for patients with dementia rests with the informal caregivers, for example, family and friends. ${ }^{1-13}$ In the USA, for example, carers provide $\sim 80 \%$ of the care for people with Alzheimer's disease and other dementias. ${ }^{14}$ It is therefore essential that carers are supported in the vital role they play. Although many developed countries have support programmes for carers, being a carer of someone with dementia is still challenging and often detrimental to carers' own health and well-being. ${ }^{15} 16$ Therefore, governments are focusing their finite resources on public health initiatives to reduce the risk factors, early detection and appropriate care and support for people with dementia and their carers. In line with this, a key recommendation of the World Alzheimer Report (2015) is to develop the dementia care workforce. The report advises government policy, and subsequently the providers of care should ensure that the dementia care workforces are adequately trained to provide person-centred care. ${ }^{15} \mathrm{~A}$ means of taking this agenda forward is through the development of integrated care pathways and support mechanisms, which in turn are facilitated by interprofessional collaboration. ${ }^{16}$ However, working together in an effective interprofessional manner is often undermined by a lack of understanding of the nature and scope of responsibility among healthcare professionals. ${ }^{17} 18$

Interprofessional education (IPE) has long been regarded the cornerstone to the provision of the knowledge and skills necessary to deliver collaborative practice. ${ }^{19-21}$ Definitions of IPE vary but for the purposes of this review it is defined as two or more professions learning with and from each other. ${ }^{22}$ Such learning is enacted across academic and work-based settings embedded in prequalification and postqualification education/training. Earlier literature reviews focusing on a number of health conditions have indicated that this form of education can be effective in providing learners with a range of abilities to collaborate in the delivery of care across various clinical settings. ${ }^{19} 2324$ However, to date, no reviews, which provide a specific focus on reporting the effects of IPE on the care of people diagnosed with dementia and their carers, have been undertaken.

This review therefore aimed to identify, describe and evaluate the impact of IPE interventions in dementia care. The review was based on the following specific questions:

1. What is the evidence that IPE for providers involved in dementia care has benefits for: (a) patient (health) outcomes, (b) family carer outcomes, (c) provider (including students) education and (d) organisational and delivery of dementia care?

2. Does the implementation of IPE improve collaborative knowledge, skills and interprofessional practice?

3. What are the outcomes of IPE in dementia care?

\section{METHODS}

We applied a pre-existing systematic review protocol to search for studies that described the evidence for the reported effects of IPE on collaborative knowledge and skills for staff involved in the delivery of dementia care. ${ }^{25}$ Article inclusion and data analysis followed PRISMA guidelines, ${ }^{26}{ }^{27}$ and the protocol was registered with PROSPERO the international prospective register of systematic reviews at the Centre for Reviews and Dissemination, University of York; registration number CRD42014015075.

\section{Search strategy}

The search strategy included a systematic search of electronic databases, supplemented by hand searching relevant journals and reference checking of included articles. A MEDLINE search strategy was developed, which was adjusted to run on another eight databases (EMBASE, The Cochrane Library, PsycINFO, CINAHL Plus, Applied Social Sciences Index and Abstracts (ASSIA), Healthcare Management Information Consortium, ERIC and British Education Index). The results of the electronic database searches were limited to the past 10 years (from 2004 to 2014) and to articles written in English. The search strategy was performed from 9 September 2014 and updated on 3 August 2015. For detailed search strategies, see online supplementary additional file 1 .

Additional studies were identified by:

- Manual searching of three journals with a considerable number of published papers on IPE and dementia (January 2004 to December 2014; Journal of Interprofessional Care, International Psychogeriatrics; Dementia: The International Journal of Social Research and Practice);

- Checking the reference lists of key articles (ie, included studies; pertinent studies);

- Consulting corresponding authors of key studies to identify any other relevant articles.

\section{Inclusion/exclusion criteria}

Research articles were included if they (a) focused on health and social care students and/or providers in dementia care, (b) evaluated the outcomes of IPE interventions (eg, classroom-based, practice-based, simulation and/or online IPE activities) either delivered alone or in combination with other interventions and (c) reported study results using quantitative, qualitative or mixed methods designs. In addition, articles were included if they primarily reported educational and/or organisational outcomes for professionals or if they focused on any reported changes in outcomes for people with dementia or their carers. Articles were excluded if they (a) did not involve people with dementia, (b) did not evaluate an IPE intervention and (c) did not report empirical findings. Systematic reviews, commentaries, non-peer-review articles and unpublished literature were excluded from the review. 


\section{Data extraction and quality appraisal}

All duplicate citations were removed before two members of the review team independently reviewed the titles and abstracts for possible inclusion. Full-paper articles of any relevant titles/abstracts were obtained and again reviewed independently by two reviewers. Any discrepancies between reviewers over selection were resolved by a third reviewer.

For each included study, two reviewers independently extracted the following data using a standardised data extraction form:

1. General information (eg, study objectives, research design and data collected);

2. IPE intervention information (eg, participant profession, type of IPE activities provided);

3. Reported outcomes (study findings);

4. Quality of study information (assessment of methodological quality).

Research study quality was evaluated using the quality checklist for quantitative or qualitative studies developed by Kmet et al (2004). ${ }^{28}$ Additionally, the criteria recommended by the GRADE Working Group to assess the strength of the body of evidence across particular study outcomes were employed. ${ }^{28}{ }^{29}$ Evidence for each reported outcome was graded as: (I) high, (II) moderate, (III) low or (IV) very low according to the GRADE rating system. This process was also undertaken independently by two reviewers, with any disagreements resolved through discussion with a third reviewer.

\section{Data synthesis strategy}

A meta-analysis of results was not appropriate because of the heterogeneity of types of study and outcomes measured. Therefore, a narrative synthesis was undertaken to integrate findings from the included studies reporting the nature of the IPE intervention and quality of the included studies. Included studies were grouped into the outcome type using a modified Kirkpatrick's model $^{20}$ to classify IPE outcomes (see table 1 ).

\section{RESULTS}

The flow chart representing study selection, including reasons for exclusion, is summarised in figure 1. The included studies underwent methodological quality assessment. ${ }^{30}$ The studies that met the inclusion criteria numbered six. ${ }^{31-36}$

\section{Intervention characteristics}

The included studies involved a range of different types of IPE activities, undertaken in different settings, with different participants and involved varying content, delivery mode and duration. Three of the included studies were conducted in the USA; $;^{32} 34{ }^{36}$ one was undertaken in Australia, ${ }^{31}$ one in $\mathrm{Canada}^{33}$ and one in the $\mathrm{UK}^{35}$ (table 2). Participants in three studies included providers of health and social care caring for people with dementia, ${ }^{32} 33{ }^{35}$ whereas three studies focused on graduate/undergraduate students receiving dementia care training. 313436

Three studies involved practice-based IPE interventions: one was delivered in primary care ${ }^{33}$ one in a community setting ${ }^{34}$ and one in an acute trust. ${ }^{35}$ Two studies focused on a classroom-based IPE interventions delivered in a university, ${ }^{31} 36$ whereas another was implemented across three sites (a teaching hospital and two managed care systems) and was classroom and practicebased. $^{32}$

In terms of specific details regarding each of the included studies, Cartwright et al's ${ }^{31}$ study used mixed methods to investigate whether participation in an online IPE dementia case study would improve students' attitudes and self-perceived ability in working with others to care for people with dementia. Coogle $e t a i^{2}$ employed a before-after design and assessed the impact of a geriatric interprofessional team training programme on changes in team skills and attitudes about team working for the care of people with dementia.

Lee $e t a l^{33}$ assessed the effectiveness of a training programme aimed at improving detection and management

\section{Table 1 Outcomes from interprofessional education (IPE)}

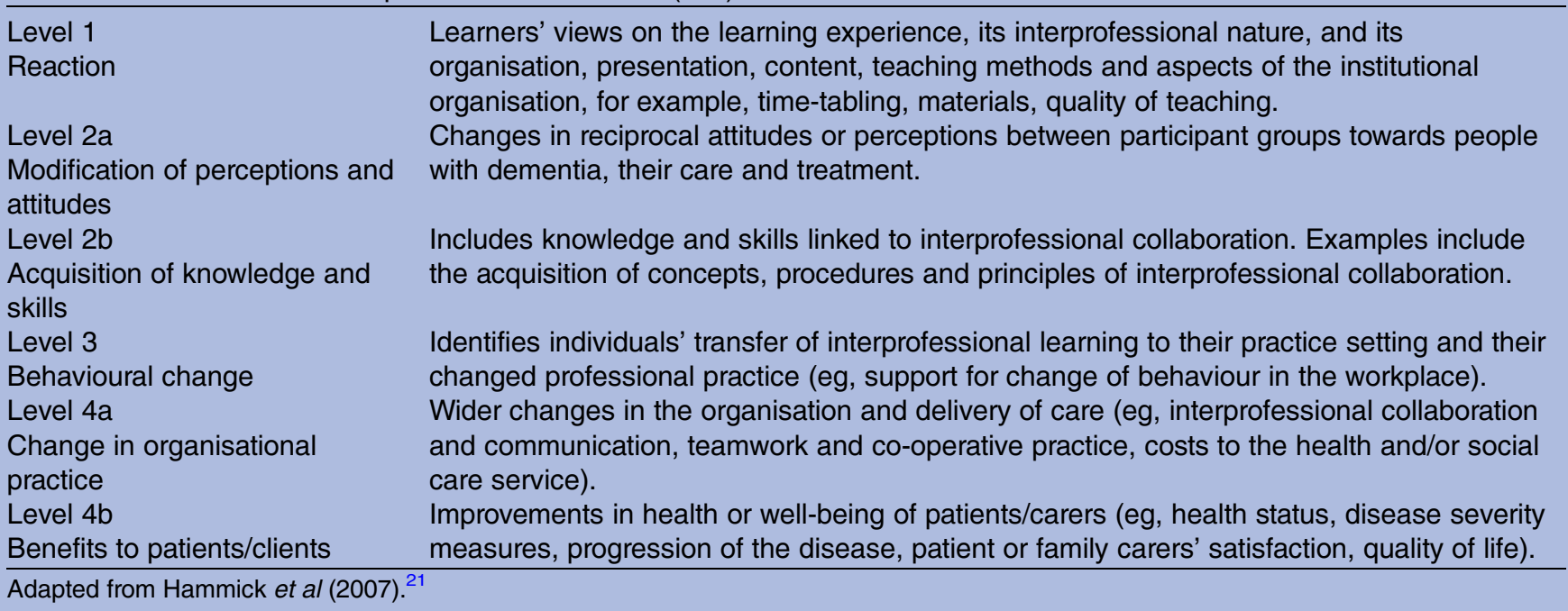




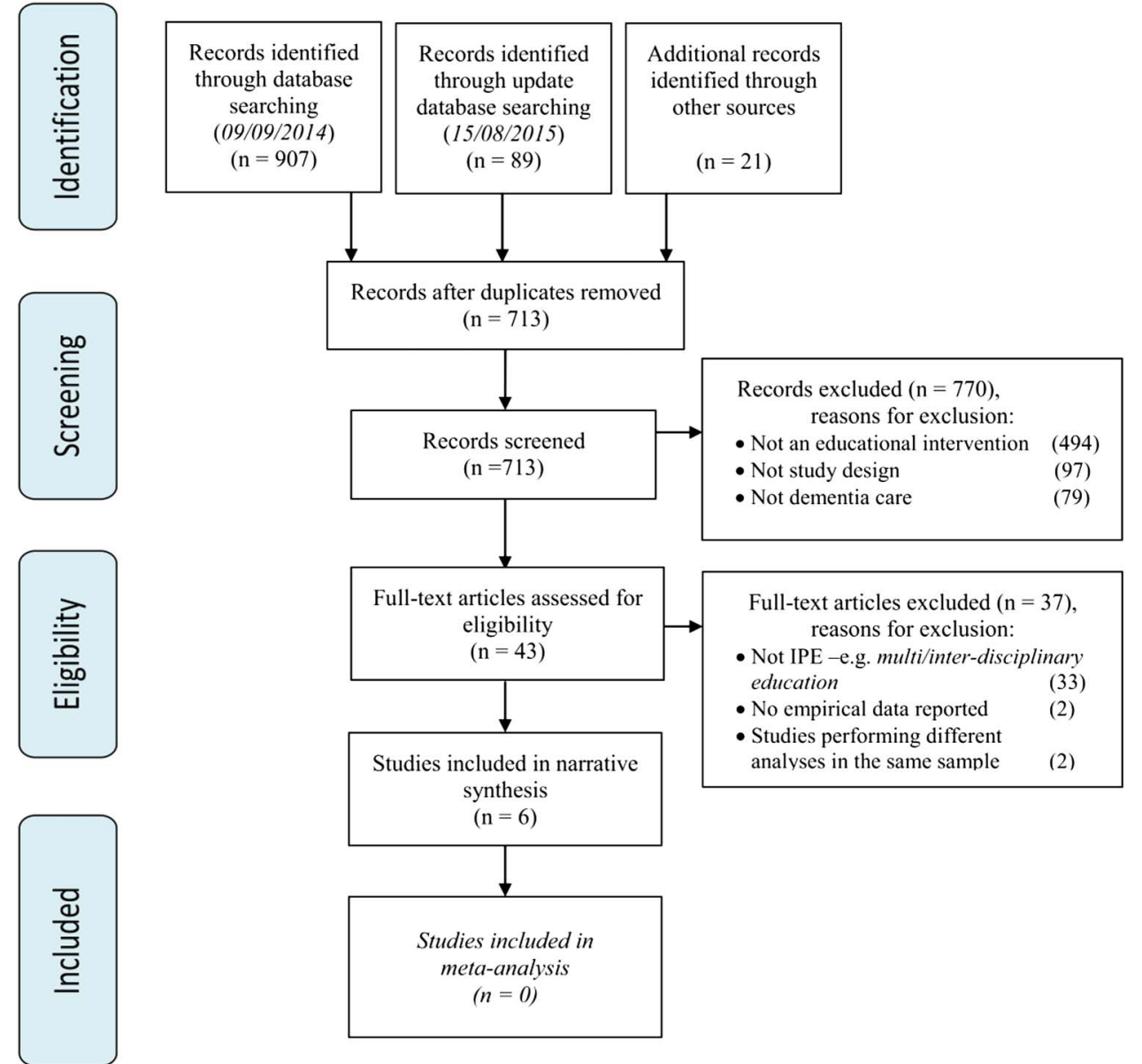

Figure 1 Selection of articles for review. IPE, interprofessional education.

of dementia by the development of a self-sustaining memory clinic-based intervention. This programme also assisted family health teams to develop collaborative knowledge and skills. The IPE intervention lasted 5 days and consisted of an interactive workshop to increase team knowledge and skills related to assessment and management of memory problems, followed by a 3-day mentorship programme.

McCaffrey et $a l,{ }^{34}$ in a study conducted in a centre for diagnosis, support and education for people with dementia and their carers, examined whether IPE could enhance medical and family nurse practitioner students' basic competency in the detection and management of Alzheimer's disease and other dementias. The IPE intervention focused on changing knowledge and skills linked to interprofessional collaboration about dementia care (within a training course).

Teodorczuk et $a l^{85}$ examined whether implementing an IPE programme could increase staff confidence in dealing with people with dementia or delirium and could thereby improve staff practice. The IPE intervention focused on three main innovative features: using an interprofessional teaching approach, learning directly from patients and carers and action learning.

Zucchero $e t a \hat{l}^{6}$ evaluated the effects of a 1-day symposium to facilitate healthcare students interdisciplinary care' for older adults with dementia. The IPE was delivered by use of a symposium during which all students reviewed common materials about team working and dementia care and a seminar aimed at facilitating teamwork.

\section{Methodological information}

Figure 2 summarises the methodological details of the included studies. Five of the studies employed quantitative approaches, whereas one study ${ }^{11}$ used mixed methods. Most studies employed a before-and-after design with only one ${ }^{34}$ using a controlled study design. In contrast, Cartwright $e t a \ell^{1}$ study employed a case study design. The studies were of variable methodological quality, ranging in overall score from $41 \%^{35}$ to $86 \%{ }^{36}$ All but two studies ${ }^{32} 33$ clearly reported their research approach for evaluating the IPE learning activities. The aim of the research was clearly and well defined in all studies.

Across the included papers, conclusions were supported by the findings. Furthermore, most of the studies reported sufficient details of the results and methodological limitations-the exception was Teodorczuk et al's ${ }^{35}$ study, where this information was considered poor. As shown in figure 2, an important methodological flaw in the studies was the absence of information to 
Table 2 Characteristics of the articles included in the review

\begin{tabular}{|c|c|c|c|c|c|c|c|}
\hline $\begin{array}{l}\text { Study } \\
\text { Location }\end{array}$ & Methods & Aim & $\begin{array}{l}\text { (A) Mode of delivery } \\
\text { (B) Duration }\end{array}$ & Setting & Beneficiaries & $\begin{array}{l}\text { Participating health } \\
\text { professionals }(n)\end{array}$ & $\begin{array}{l}\text { Outcomes } \\
\text { type* }\end{array}$ \\
\hline $\begin{array}{l}32 \\
\text { USA }\end{array}$ & $\begin{array}{l}\text { Preintervention/ } \\
\text { postintervention design } \\
\text { without a comparison group. } \\
\text { Baseline and } \\
\text { postintervention data } \\
\text { measured using a } \\
\text { questionnaire including: } \\
\text { (1) demographic and } \\
\text { motivational questions; } \\
\text { (2) the ATHCTS and (3) the } \\
\text { Geriatrics Attitudes Scale }\end{array}$ & $\begin{array}{l}\text { Training on how teams } \\
\text { can provide } \\
\text { well-coordinated } \\
\text { best-practice care by } \\
\text { reducing medical errors } \\
\text { and decreasing service } \\
\text { duplication }\end{array}$ & $\begin{array}{l}\text { (A) } 39 \text { different half-day } \\
\text { training sessions } \\
\text { delivered in three } \\
\text { healthcare systems } \\
\text { (B) } 156 \text { hours }\end{array}$ & $\begin{array}{l}\text { 1. Teaching } \\
\text { hospital } \\
\text { 2. Managed } \\
\text { care } \\
\text { organisations }\end{array}$ & $\begin{array}{l}\text { Professionals } \\
\text { delivering } \\
\text { dementia care }\end{array}$ & $\begin{array}{l}\text { Nursing (34) } \\
\text { Social work (9) } \\
\text { Rehabilitation (10) } \\
\text { Other (8) } \\
\text { Total }(61)\end{array}$ & $\begin{array}{l}2 a \\
2 b\end{array}$ \\
\hline $\begin{array}{l}34 \\
\text { USA }\end{array}$ & $\begin{array}{l}\text { Preintervention/ } \\
\text { postintervention design with } \\
\text { a comparison group. } \\
\text { Baseline and } \\
\text { postintervention data } \\
\text { measured using (1) } \\
\text { investigator-created } \\
\text { semantic differential scale } \\
\text { items on attitudes and true- } \\
\text { false test on knowledge } \\
\text { towards individuals with AD } \\
\text { and (2) the ATHCTS }\end{array}$ & $\begin{array}{l}\text { To use an } \\
\text { interprofessional } \\
\text { approach to increase } \\
\text { students' understanding } \\
\text { of the roles they and } \\
\text { other professionals play }\end{array}$ & $\begin{array}{l}\text { (A) } 4 \text { hour session }+5 \\
\text { clinical 'experiences' in } \\
\text { dyads (nurse and medical } \\
\text { students) observing a } \\
\text { nurse. } \\
\text { (B) Each dyad } \\
\text { participated in five clinical } \\
\text { experiences over a } \\
\text { 15-week semester }\end{array}$ & $\begin{array}{l}\text { Memory and } \\
\text { wellness centre }\end{array}$ & $\begin{array}{l}\text { Students training } \\
\text { in dementia care }\end{array}$ & $\begin{array}{l}\text { Medicine (74) } \\
\text { Nursing (46) } \\
\text { Total (120) }\end{array}$ & $\begin{array}{l}2 a \\
2 b\end{array}$ \\
\hline
\end{tabular}




\begin{tabular}{|c|c|c|c|c|c|c|c|}
\hline $\begin{array}{l}\text { Study } \\
\text { Location }\end{array}$ & Methods & Aim & $\begin{array}{l}\text { (A) Mode of delivery } \\
\text { (B) Duration }\end{array}$ & Setting & Beneficiaries & $\begin{array}{l}\text { Participating health } \\
\text { professionals }(\mathrm{n})\end{array}$ & $\begin{array}{l}\text { Outcomes } \\
\text { type* }\end{array}$ \\
\hline $\begin{array}{l}35 \\
\text { UK }\end{array}$ & $\begin{array}{l}\text { Preintervention/ } \\
\text { postintervention design } \\
\text { without a comparison group. } \\
\text { Baseline and } \\
\text { postintervention data } \\
\text { measured using a } \\
\text { questionnaire based on a } \\
\text { five-point Likert scale }\end{array}$ & To improve staff practice & $\begin{array}{l}\text { (A) 2-day course } \\
\text { Day 1: challenged beliefs } \\
\text { and about the confused } \\
\text { older patient } \\
\text { Day 2: focused on } \\
\text { managing complex cases } \\
\text { and practice change } \\
\text { (B) } 3 \text { times over } \\
18 \text { months }\end{array}$ & Acute trust & $\begin{array}{l}\text { Professionals } \\
\text { delivering } \\
\text { dementia care }\end{array}$ & $\begin{array}{l}\text { Nursing (15) } \\
\text { HealthcareAssistant } \\
\text { (8) } \\
\text { Physiotherapy (5) } \\
\text { Modern matron (5) } \\
\text { Medicine (3) } \\
\text { Physiotherapy (3) } \\
\text { Other (9) } \\
\text { Total (48) }\end{array}$ & $2 b$ \\
\hline $\begin{array}{l}36 \\
\text { USA }\end{array}$ & $\begin{array}{l}\text { Preintervention/ } \\
\text { postintervention design } \\
\text { without a comparison group. } \\
\text { Baseline and } \\
\text { postintervention data } \\
\text { measured using the } \\
\text { ATHCTS }\end{array}$ & $\begin{array}{l}\text { To evaluate the } \\
\text { interdisciplinary approach } \\
\text { to treating older adults } \\
\text { with dementia }\end{array}$ & $\begin{array}{l}\text { (A) Symposium: 1, (pre) } \\
\text { all students reviewed a } \\
\text { common article about } \\
\text { interdisciplinary team } \\
\text { process, } \\
\text { discipline-specific } \\
\text { readings and an assigned } \\
\text { case study. 2, (during) (a) } \\
\text { didactic lecture about } \\
\text { dementia care; (b) } \\
\text { interprofessional team } \\
\text { meetings; (c) large group } \\
\text { feedback session; } \\
\text { (B) A one day } 5 \text { hour } \\
\text { symposium }\end{array}$ & University & $\begin{array}{l}\text { Graduate and } \\
\text { undergraduate } \\
\text { students training } \\
\text { in dementia care }\end{array}$ & $\begin{array}{l}\text { Nursing (36) } \\
\text { Administration (27) } \\
\text { Occupational } \\
\text { therapy (26) } \\
\text { Counselling (8) } \\
\text { Social work (6) } \\
\text { Psychology (6) } \\
\text { Total (109) }\end{array}$ & $2 a$ \\
\hline
\end{tabular}

*Kirkpatrick level.

AcD, academic detailing; AD, Alzheimer's disease; ATHCTS, Attitudes Toward Healthcare Teams Scale; FHT, family health centre; ITT, interdisciplinary team training. 
Figure 2 Methodological quality for included studies. ${ }^{31-36}$

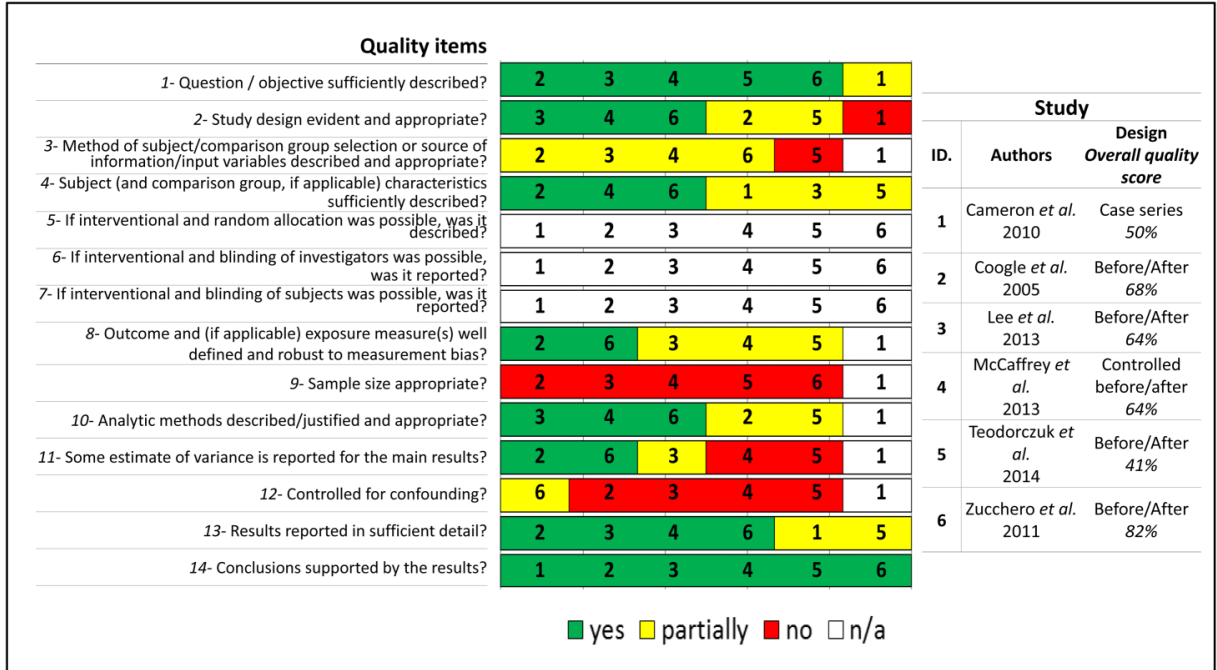

evaluate sample size adequacy. Failure to adjust the analysis for confounding variables and not providing information about uncertainty of estimates in reporting the main results were also two main limitations.

\section{Reported outcomes}

Four IPE interventions focused on changing reciprocal attitudes among health providers towards dementia care and treatment-level 2a outcomes. ${ }^{31} 323436$ Four of the studies reported outcomes related to acquisition of collaborative knowledge and skills linked to interprofessional collaboration in caring for people with dementia -level 2a. ${ }^{32-35}$ Only one study ${ }^{33}$ investigated changes in reaction, behavioural change and organisational practice -levels 1, 3 and 4a. None of the studies assessed outcomes related to patients and/or carers-level $4 \mathrm{~b}$ of the Kirkpatrick model.

Table 3 provides a summary of the learning outcomes classified using a modified Kirkpatrick model as described above (see table 1) and the overall quality of the evidence per outcome as assessed with GRADE.

This section goes on to provide more details about the outcomes of the included studies and the methodological quality:

Reaction (level 1)

Only one study ${ }^{33}$ reported the learners' views of their experience of learning. These authors found that the use of interprofessional case study discussions and formal presentations resulted in improved learner perceptions. Given the nature of the methodological quality of the studies in this category, the evidence was rated as 'very low'.

Modification and perceptions of attitude (level 2a)

The four studies that focused on this category of learning outcome showed that the use of IPE is likely to facilitate a better attitude about other professionals' role in the delivery of dementia care. ${ }^{31} 323435$ Overall, the evidence provided by these studies was rated as 'low'.

Acquisition of knowledge and skills (level 2b)
The four studies investigating outcomes relating to acquisition of knowledge/skills found that the use of an IPE approach in providers delivering dementia care may lead to improved team skills, collaborative knowledge and ability to manage cognitive impairments and dementia care. ${ }^{32-35}$ Given the high risk of bias of this research, the evidence supporting the positive effects of IPE was rated as 'low'.

Behavioural change (level 3)

Only one study ${ }^{33}$ described changes in practice as a result of interprofessional learning. The reported change was greater use of standardised patient assessment tools (the assessment for cognitive impairment and fitness to drive). There was also an increased use of a clinical reasoning model by participants in their work. However, the evidence to support the transfer of learning into practice was graded of 'low' quality.

Changes in organisational practice (level 4a)

Lee $e t a l$ s study reported wider organisational changes that impacted on the delivery of dementia care, as a result of its IPE intervention. The changes comprised establishing a memory clinic in the primary care setting. ${ }^{33}$ However, the effects were uncertain because the quality of the evidence was 'very low'.

\section{DISCUSSION}

This systematic review investigated the evidence of the reported effects of IPE on collaborative knowledge and skills, interprofessional practice and the delivery of dementia care. As presented above, the review identified six relevant IPE studies, which in terms of their methodological quality were generally weak. As a result, the evidence for the use of IPE in dementia care suggests that its effects are uncertain for outcome levels 1-4a, with no evidence for level $4 \mathrm{~b}$-effects of IPE in dementia care on patient or family carers' outcomes.

Indeed, the strength of this body of evidence for IPE in the care for people with dementia was assessed to be either 'low' or 'very low'. Specifically, we found low- 
Table 3 Summary of learning outcomes

\begin{tabular}{|c|c|c|c|}
\hline Outcomes* $^{*}$ & Main findings (as reported by the authors) & Study & $\begin{array}{l}\text { Quality of the } \\
\text { evidence* }\end{array}$ \\
\hline Level 1 & $\begin{array}{l}\text { "There were no statistically significant differences." page } 27 \\
\text { "Mean ratings of participants' perceptions were highest for case study } \\
\text { discussions and formal presentations, and lowest, but still high, for multimedia } \\
\text { presentations." page } 27 \\
\text { "Participants' ratings of the usefulness of the mentorship component of the } \\
\text { program reflected that mentorship opportunities were extremely useful for } \\
\text { knowledge transfer." page } 28\end{array}$ & 33 & Very low quality \\
\hline \multirow[t]{4}{*}{ Level 2a } & $\begin{array}{l}\text { "Students had an increased appreciation of the importance of teamwork and } \\
\text { client-centred care when working with people with dementia and complex } \\
\text { health-care needs." } \\
\text { "Furthermore, the qualitative results supported an increase in interprofessional } \\
\text { socialisation and values, which foster collaborative teamwork." page } 92\end{array}$ & 31 & Low quality \\
\hline & $\begin{array}{l}\text { "Results suggest that individuals who have worked longer in the health care } \\
\text { system are more likely to perceive the value of teams in the pursuit of quality } \\
\text { care and to develop improved attitudes about geriatric care as a consequence } \\
\text { of educational interventions." page } 155\end{array}$ & 32 & \\
\hline & $\begin{array}{l}\text { "Improved attitudes toward interprofessional teamwork and collaboration were } \\
\text { evident in trainees' responses to open-ended questions about the experience." } \\
\text { page } 536\end{array}$ & 34 & \\
\hline & $\begin{array}{l}\text { "Student attitudes toward health care teams were more positive after the } \\
\text { symposium." page } 405\end{array}$ & 36 & \\
\hline \multirow[t]{4}{*}{ Level 2b } & $\begin{array}{l}\text { "Results ... demonstrate that more than } 4 \text { hours of training are required to } \\
\text { demonstrate self-reported improvements in team skills and attitudes about the } \\
\text { costs of team care." page } 152\end{array}$ & 32 & Low quality \\
\hline & $\begin{array}{l}\text { "There were statistically significant increases in self-reported knowledge of and } \\
\text { ability to assess and manage cognitive impairment, confidence, comfort level } \\
\text { in speaking to patients and caregivers about memory problems and the ability } \\
\text { of participants' FHT to manage cognitive impairment independently." page } 28\end{array}$ & 33 & \\
\hline & $\begin{array}{l}\text { "Significant outcomes of this program included increased knowledge about AD } \\
\text { on the multiple choice test in the nurse practitioner students." page } 535\end{array}$ & 34 & \\
\hline & $\begin{array}{l}\text { "There has been a significant improvement in the learners' confidence in } \\
\text { managing issues relevant to this patient group..."'The course evaluation and } \\
\text { posters also suggested positive changes in knowledge and attitude." page } 499\end{array}$ & 35 & \\
\hline Level 3 & $\begin{array}{l}\text { "There were no statistically significant differences..." page } 27 \text { "Practice changes } \\
\text { were reported more frequently for use of standardised tools for assessing } \\
\text { cognitive impairment and executive functioning, screening for fitness to drive } \\
\text { and use of a clinical reasoning model." page } 28\end{array}$ & 33 & Very low quality \\
\hline Level $4 a$ & $\begin{array}{l}\text { "All but } 1 \text { of the participating FHTs (number }=23 \text { ) established a memory clinic } \\
\text { within their primary care setting that was sustainable over time." page } 28\end{array}$ & 33 & Very low quality \\
\hline Level $4 \mathrm{~b}$ & - & - & - \\
\hline
\end{tabular}

High quality: Further research is very unlikely to change our confidence in the estimate of effect. Moderate: Further research is likely to have an important impact on our confidence in the estimate of effect and may change the estimate. Low: Further research is very likely to have an important impact on our confidence in the estimate of effect and is likely to change the estimate. Very low quality: any estimate of effect is very uncertain.

*GRADE Working Group rating system. ${ }^{28} 29$

AcD, academic detailing; AD, Alzheimer's disease; ATHCTS, Attitudes Toward Healthcare Teams Scale; FHT, family health centre; ITT, interdisciplinary team training.

quality evidence, suggesting that the implementation of IPE improves collaborative knowledge, skills and interprofessional practice in health and social care providers and students involved in caring for people with dementia. ${ }^{30} 3133-35$ We also found 'low' quality evidence, suggesting that IPE may improve the reciprocal attitudes between participant groups towards people with dementia, their care and treatment.

To the best of our knowledge, this is the first systematic review summarising the evidence for the value of
IPE dementia education programmes on learning outcomes of health and social care providers and students. Accordingly, the findings cannot be compared with other studies. However, parallels may be drawn with findings from this review and with the results of previous reviews, which have also found limited evidence that IPE can improve professional practice and health and social care outcomes, for example, in child protection, delirium care, diabetes care and domestic violence management. 2137 


\section{Strengths and weaknesses of the review}

Strengths of this review include prospective protocol registration with PROSPERO, ${ }^{25}$ which was followed thoroughly. The review methods were also based on the Preferred Reporting Items for Systematic review and Meta-analysis Protocols (PRISMA-P) 2015 statement, ${ }^{38}$ a rigorous system for undertaking systematic reviews. The results in this review are therefore likely to provide a comprehensive review of how IPE is being used in dementia care-comparable with other IPE systematic work.

This systematic review also has a number of limitations. First, it was limited to studies published in English, and therefore the findings may be affected from the so-called 'language bias'. 3940 Second, the literature on IPE in dementia care was limited and heterogeneous; therefore, search and selection bias may be occurred. ${ }^{41}$ Third, to provide a current state of evidence, only studies published in the past 10 years were included in this review, and thus our results may be biased in terms of 'time-lag bias'.

\section{Implications for practice and future research}

This review identified only six studies that described IPE interventions whose aim was to improve collaborative knowledge, skills, interprofessional practice and organisational awareness of dementia and dementia care. However, the evidence was generally weak due to limitations such as self-selection bias and the use of small convenience samples. In addition, most of the included studies used weak research designs that were unable to differentiate between direct effects of the IPE intervention (such as acquisition of knowledge and skills) versus the added value of contextual constraints and opportunities (such as requirements for professional registration, funding, tutors' expertise and participants' prior learning and beliefs). Nevertheless, these findings can inform a future agenda for research focused on developing higher quality IPE studies for professionals working in the delivery of care for people with dementia.

\section{CONCLUSIONS}

The world's ageing population and the associated rise in the number of people with dementia is of international concern. The impact of this significant public health issue extends across the social, economic and political domains of society. On a personal level, it may affect an individual's agency for independent living and have a negative impact on those caring for family members with dementia. The World Alzheimer Report (2013) recommended that health and social care professionals are adequately trained in order to provide personcentred care for those with dementia and those who support them. ${ }^{42}$ IPE providing professionals with effective evidence-based tools to identify what they could bring to the management of dementia collectively offers a possible way to improve interprofessional collaboration and care for those with dementia and their families.
Contributors FP, NG and SR designed the research protocol and performed the preliminary searches. MJ, NG, SR and FP coauthored substantial parts of the manuscript and reviewed all draft versions. All authors reviewed the identified articles for inclusion, abstracted data and participated in writing the manuscript. The final version of this article has been seen and approved by all authors.

\section{Competing interests None declared.}

Provenance and peer review Not commissioned; externally peer reviewed.

Data sharing statement Data are not shared but may be found in the six studies critically reviewed as part of this review. No additional unpublished data are available for this study.

Open Access This is an Open Access article distributed in accordance with the Creative Commons Attribution Non Commercial (CC BY-NC 4.0) license, which permits others to distribute, remix, adapt, build upon this work noncommercially, and license their derivative works on different terms, provided the original work is properly cited and the use is non-commercial. See: http:// creativecommons.org/licenses/by-nc/4.0/

\section{REFERENCES}

1. Chong MS, Sahadevan S. An evidence-based clinical approach to the diagnosis of dementia. Ann Acad Med Singap 2003;32:740-8.

2. Sosa-Ortiz AL, Acosta-Castillo I, Prince MJ. Epidemiology of dementias and Alzheimer's disease. Arch Med Res 2012;43:600-8.

3. Licastro F, Carbone I, Raschi E, et al. The 21st century epidemic: infections as inductors of neuro-degeneration associated with Alzheimer's disease. Immun Ageing 2014;11:22.

4. World Health Organization and Alzheimer's Disease International. Dementia: A Public Health Priority. 2012. http://www.who.int/mental_ health/publications/dementia_report_2012/en/ (accessed 14 Dec 2015)

5. Larson EB, Yaffe K, Langa KM. New insights into the dementia epidemic. N Engl J Med 2013;369:2275-7.

6. World Health Organization. The world health report, Chapter 1 : Global Health: today's challenges. 2003. http://www.who.int/whr/ 2003/en/Chapter1-en.pdf?ua=1 (accessed 14 Dec 2015).

7. Prince M, Bryce R, Albanese $\mathrm{E}$, et al. The global prevalence of dementia: a systematic review and metaanalysis. Alzheimers Dement 2013;9:63-75.e2.

8. Matthews FE, Arthur A, Barnes LE, et al. A two-decade comparison of prevalence of dementia in individuals aged 65 years and older from three geographical areas of England: results of the cognitive function and ageing study I and II. Lancet 2013;382:1405-12.

9. Wimo A, Winblad B, Jönsson L. An estimate of the total worldwide societal costs of dementia in 2005. Alzheimers Dement 2007;3:81-91.

10. Drennan VM, Greenwood N, Cole L, et al. Conservative interventions for incontinence in people with dementia or cognitive impairment, living at home: a systematic review. BMC Geriatr 2012;12:77

11. Ferri CP, Prince M, Brayne C, et al. Global prevalence of dementia: a Delphi consensus study. Lancet 2005;366:2112-17.

12. Wimo A, Jönsson L, Bond J, et al. The worldwide economic impact of dementia 2010. Alzheimers Dement 2013;9:1-11.e3.

13. National Audit Office. Improving services and support for people with Dementia. London: National Audit Office, 2007.

14. Alzheimer's Association. 2012 Alzheimer's disease facts and figures Alzheimers Dement 2012;8:131-68.

15. Pinquart M, Sörensen S. Correlates of physical health of informal caregivers: a meta-analysis. J Gerontol B Psychol Sci Soc Sci 2007;62:P126-37

16. Alzheimer's Disease International, 2015. World Alzheimer Report 2015: The global impact of dementia. An analysis of prevalence, incidence, cost and trends. London: ADI. https://www.alz.co.uk/ research/WorldAlzheimerReport2015.pdf (accessed online August 2015).

17. Warshaw GA, Bragg EJ. Preparing the health care workforce to care for adults with Alzheimer's disease and related dementias. Health Aff (Millwood) 2014;33:633-41.

18. Cowley S, Bliss J, Mathew A, et al. Effective interagency and interprofessional working: facilitators and barriers. Int $J$ Palliat Nurs 2002;8:30-9.

19. van Schaik SM, O'Brien BC, Almeida SA, et al. Perceptions of interprofessional teamwork in low-acuity settings: a qualitative analysis. Med Educ 2014;48:583-92.

20. Barr H, Koppel I, Reeves S, et al. Effective interprofessional education: argument, assumption and evidence. Oxford: Blackwell, 2005. 
21. Hammick M, Freeth D, Koppel I, et al. A best evidence systematic review of interprofessional education: BEME Guide no. 9. Med Teach 2007;29:735-51.

22. Reeves S, Perrier L, Goldman J, et al. Interprofessional education: effects on professional practice and healthcare outcomes (update) Cochrane Database Syst Rev 2013;(3):CD002213.

23. Centre for the Advancement of Interprofessional Education (CAIPE), 2002. Defining IPE. Fareham: CAIPE. http://www.caipe.org.uk/ aboutus/defining-ipe (accessed 14 Dec 2015).

24. Robben S, Perry M, van Nieuwenhuijzen L, et al. Impact of interprofessional education on collaboration attitudes, skills, and behavior among primary care professionals. J Contin Educ Health Prof 2012;32:196-204.

25. Darlow B, Coleman K, McKinlay E, et al. The positive impact of interprofessional education: a controlled trial to evaluate a programme for health professional students. BMC Med Educ 2015;15:98.

26. Pelone F, Reeves S, loannides A, et al. Interprofessional education in the care of people diagnosed with dementia: protocol for a systematic review. BMJ Open 2015;5:e007490.

27. Moher D, Liberati A, Tetzlaff J, et al. Preferred reporting items for systematic reviews and meta-analyses: the PRISMA statement. BMJ 2009;339:b2535.

28. Kmet LM, Lee RC, Cook LS. Standard quality assessment criteria for evaluating primary research papers from a variety of fields. Edmonton: Alberta Heritage Foundation for Medical Research (AHFMR), 2004; HTA Initiative HTA Initiative, 02(13). http://www.ihe. ca/documents/HTA-FR13.pdf (accessed 28 Oct 2015).

29. Atkins D, Best D, Briss PA, et al. Grading quality of evidence and strength of recommendations. BMJ 2004;328:1490.

30. Guyatt GH, Oxman AD, Kunz R, et al. What is "quality of evidence" and why is it important to clinicians? BMJ 2008;336:995-8.

31. Cartwright J, Franklin D, Forman D, et al. Promoting collaborative dementia care via online interprofessional education. Australas J Ageing 2015;34:88-94.

32. Coogle CL, Parham IA, Cotter JJ, et al. A professional development program in geriatric interdisciplinary teamwork: Implications for managed care and quality of care. J Appl Gerontol 2005;24:142-59.

33. Lee L, Weston WW, Hillier LM. Developing memory clinics in primary care: an evidence-based interprofessional program of continuing professional development. J Contin Educ Health Prof 2013;33:24-32

34. McCaffrey R, Tappen RM, Lichtstein DM, et al. Interprofessional education in community-based Alzheimer's disease diagnosis and treatment. J Interprof Care 2013;27:534-6.

35. Teodorczuk A, Mukaetova-Ladinska E, Corbett S, et al. Learning about the patient: an innovative interprofessional dementia and delirium education programme. Clin Teach 2014;11:497-502.

36. Zucchero RA, Hooker EA, Harland B, et al. Maximizing the impact of a symposium to facilitate change in student attitudes about interdisciplinary teamwork. Clin Gerontologist 2011;34:399-412.

37. Sockalingam S, Tan A, Hawa R, et al. Interprofessional education for delirium care: a systematic review. $J$ Interprof Care 2014;28:345-51.

38. Shamseer L, Moher D, Clarke M, et al. Preferred reporting items for systematic review and meta-analysis protocols (PRISMA-P) 2015: elaboration and explanation. BMJ 2015;349:g7647.

39. Morrison A, Polisena J, Husereau D, et al. The effect of Englishlanguage restriction on systematic review-based meta-analyses: a systematic review of empirical studies. Int J Technol Assess Health Care 2012;28:138-44.

40. Pham B, Klassen TP, Lawson ML, et al. Language of publication restrictions in systematic reviews gave different results depending on whether the intervention was conventional or complementary. J Clin Epidemiol 2005;58:769-76. Erratum in: J Clin Epidemiol 2006 Feb;59(2):216.

41. Tricco AC, Tetzlaff J, Sampson M, et al. Few systematic reviews exist documenting the extent of bias: a systematic review. J Clin Epidemiol 2008;61:422-34

42. World Alzheimer Report 2013. Alzheimer's Disease International. London. http://www.alz.co.uk/research/WorldAlzheimerReport2013. pdf (accessed 28 Oct 2015). 